\title{
DIFFUSION BONDING OF SILICON CARBIDE CERAMICS USING TITANIUM INTERLAYERS
}

Michael C. Halbig, Army Research Laboratory, Vehicle Technology Directorate, Cleveland, OH; Mrityunjay Singh and Tarah P. Shpargel, QSS Group, Inc., Cleveland, OH; James D. Kiser, NASA Glenn Research Center, Cleveland, OH

Robust joining approaches for silicon carbide ceramics are critically needed to fabricate leak free joints with high temperature mechanical capability. In this study, titanium foils and physical vapor deposited (PVD) titanium coatings were used to form diffusion bonds between $\mathrm{SiC}$ ceramics using hot pressing. Silicon carbide substrate materials used for bonding include sintered $\mathrm{SiC}$ and two types of CVD SiC. Microscopy results show the formation of well adhered diffusion bonds. The bond strengths as determined from pull tests are on the order of several ksi, which is much higher than required for a proposed application. Microprobe results show the distribution of silicon, carbon, titanium, and other minor elements across the diffusion bond. Compositions of several phases formed in the joint region were identified. Potential issues of material compatibility and optimal bond formation will also be discussed. 


\title{
DIFFUSION BONDING OF SILICON CARBIDE CERAMICS USING TITANIUM INTERLAYERS
}

\author{
Michael C. Halbig ${ }^{1}$, Mrityunjay Singh², Tarah P. Shpargel ${ }^{2}$, \\ and J. Douglas Kiser ${ }^{3}$
}

1 - U.S. Army Research Laboratory, Vehicle Technology Directorate, Cleveland, Ohio

2 - QSS Group, Inc., Cleveland, Ohio

3 - NASA Glenn Research Center, Cleveland, Ohio

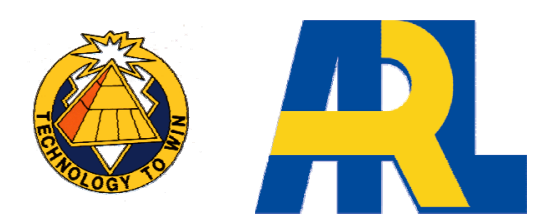

VEHICLE TECHNOLOGY DIRECTORATE
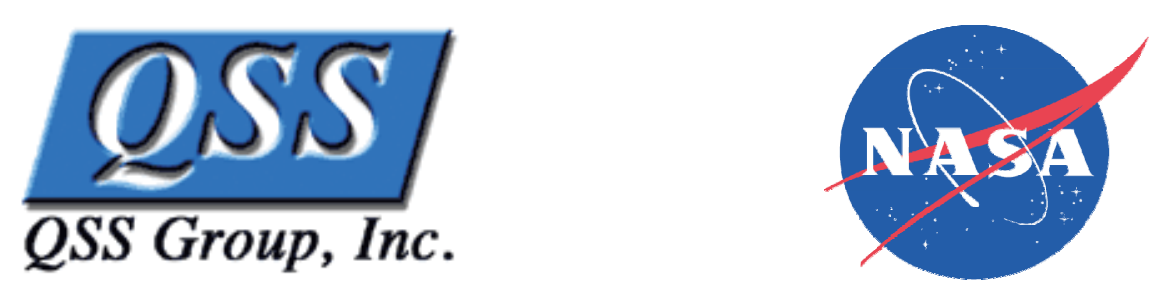

30th International Conference \& Exposition on Advanced Ceramics and Composites, Cocoa Beach, Florida, January 22-27, 2006. 


\section{Acknowledgements}

- This effort was supported by the NASA Glenn Research Center under the Intelligent Propulsion Systems Foundation Technology Sub-Project / Ultra-Efficient Engine Technology Project / Vehicle Systems Program.

- The authors would like to thank the following:

- Dr. Dan L. Bulzan and Robert R. Tacina at NASA GRC for their support and for providing the injector design and requirements.

- James Smith of QSS Group, Inc. at NASA GRC for conducting electron microprobe work.

- Dr. Robert Okojie of NASA GRC for providing PVD Ti Coated CVD SiC. 


\section{Outline}

1. Application - Micro-Electro-Mechanical Systems Lean Direct Injector (MEMS LDI) for Advanced Aircraft Gas Turbines

2. Joining Approach - Diffusion Bonding of Silicon Carbide Ceramics With a Titanium Interlayer
A. Benefits of Approach
B. Processing Matrix for Joining Technology
Development
C. Results - Microscopy

3. Summary and Conclusions 


\section{Multi-Point Lean Direct Injector}

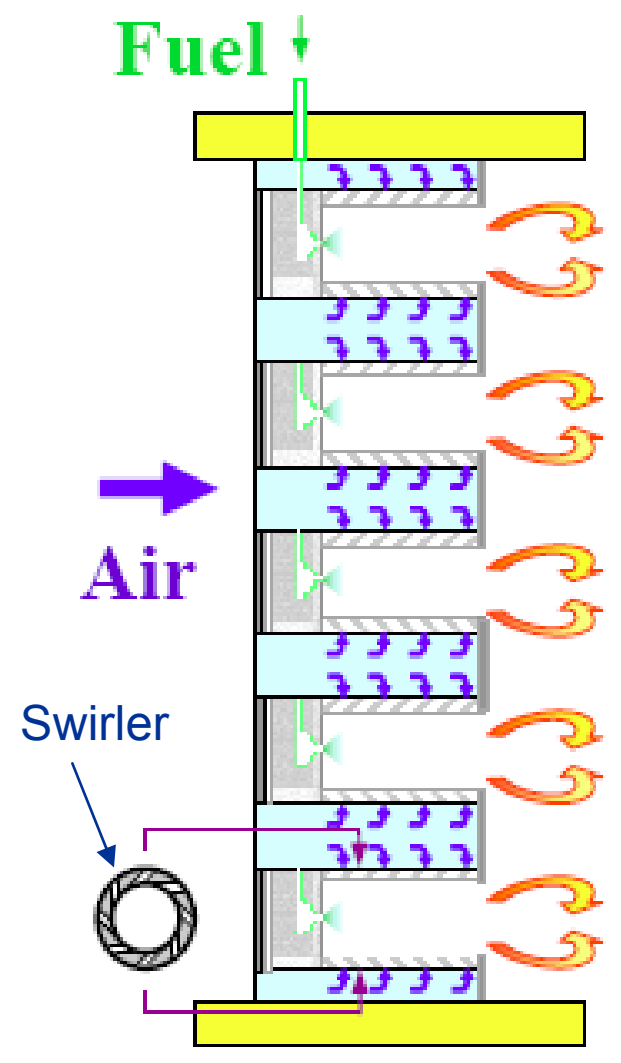

(Left) Multi-Point Lean Direct Injector accelerates fuel-air mixing and has small recirculation zones with short residence time that reduces NOx emission.

(Center) 3-inch square metal MP-LDI with 45 injectors. (Right) Detail of fuel and airflow.

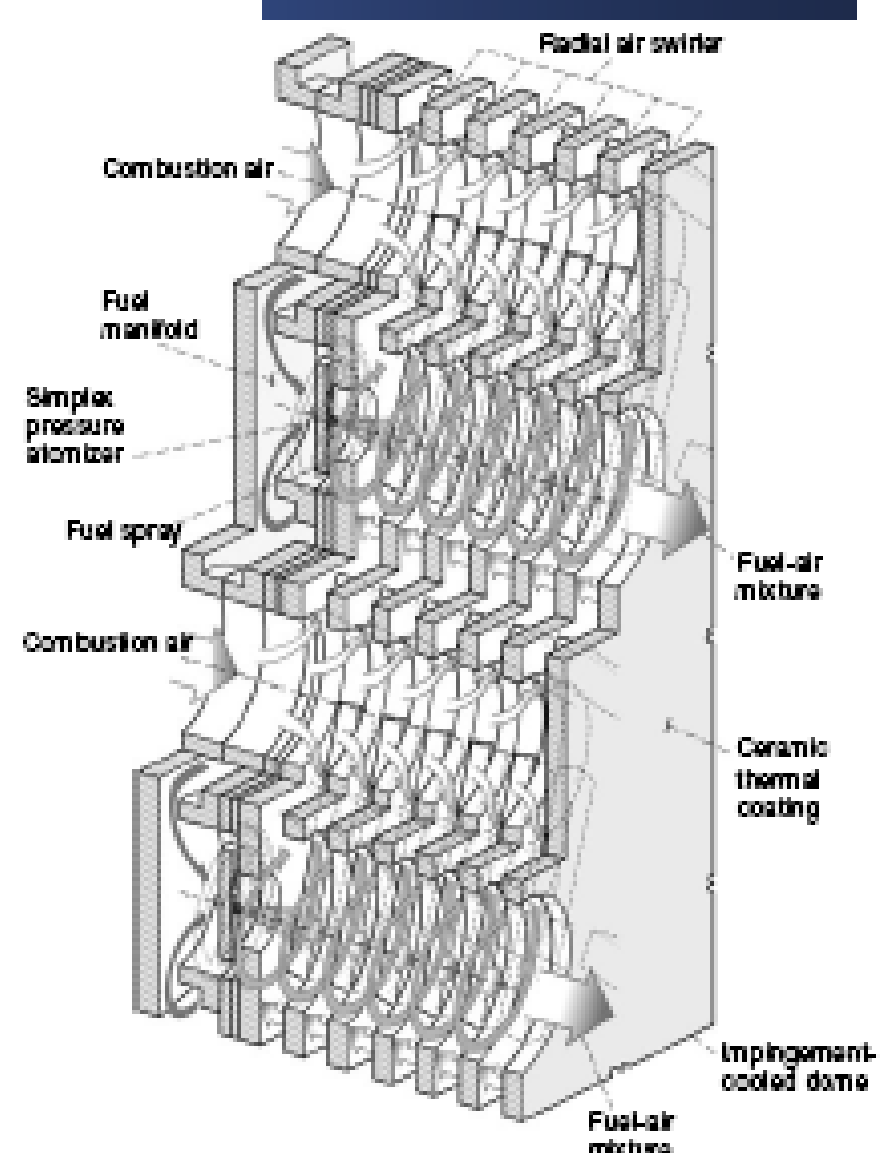

From Robert Tacina, et al., "A Low Lean Direct Injection, Multi-Point Integrated Module Combustor Concept for Advanced Aircraft Gas Turbines," NASA/TM-2002-211347, April 2002. 


\section{Lean Direct Injector Fabricated by Laminates}

SiC laminates can be used to create intricate and interlaced passages to speed up fuel-air mixing to allow lean-burning, ultra-low emissions.

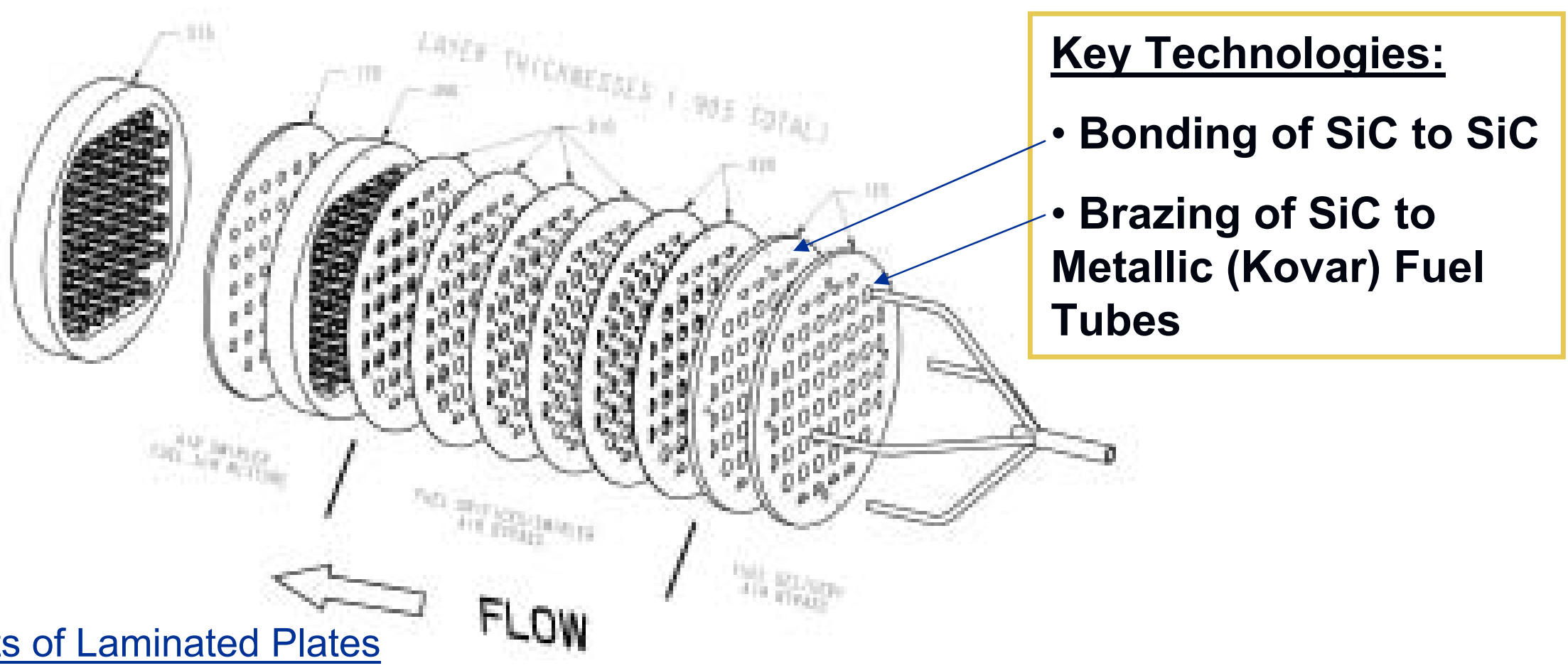

Benefits of Laminated Plates

- Passages of any shape can be created to allow for multiple fuel circuits

- Provides thermal protection of the fuel to prevent choking

- Low cost fabrication of modules with complicated internal geometries through chemical etching 


\section{Joining SiC to SiC}

Disadvantages of Previous Method of Joining with a Silicate Glass Layer

- Difficult to achieve a uniform layer

- Relatively low strength

- Silicate glass flows and fills in holes and edges where it is not desired

- Due to these disadvantages, previous glass joints were not leak-free

Advantages of Ti Layer Joining

- Uniform Ti layers can be applied

- Ti can be applied by different methods (foil, PVD, and other coating approaches)

- High strength and leak free bonds

- Good high temperature stability

The objective is to develop joining technology that has the following capabilities:

- Joining of relatively large geometries (i.e. 4" diameter disks)

- Leak-free at an internal pressure of 200 psi (1.38 MPa)

- Stability and strength retention at $800^{\circ} \mathrm{F}\left(427^{\circ} \mathrm{C}\right)$ 


\section{SiC-Ti-SiC Diffusion Bond Processing Matrix}

$\mathrm{SiC}$ and Ti Material Combinations:

1. 1.75" diameter a-SiC (CRYSTAR from Saint-Gobain) disks joined with a

1.5 mil (38 micron) foil

2. 1.75" diameter CVD SiC (TREX Enterprises) disks joined with a 1.5 mil

(38 micron) foil

3. 1" x 2" CVD SiC (Rohm \& Hass) coupons joined with $\sim 10$ micron PVD Ti coating on one of the surfaces

4. 1" x 2" CVD SiC (Rohm \& Hass) coupons joined with a 1.5 mil (38 micron) foil

5. 1" x 2" CVD SiC (Rohm \& Hass) coupons joined with 10 micron PVD Ti coating on both of the surfaces

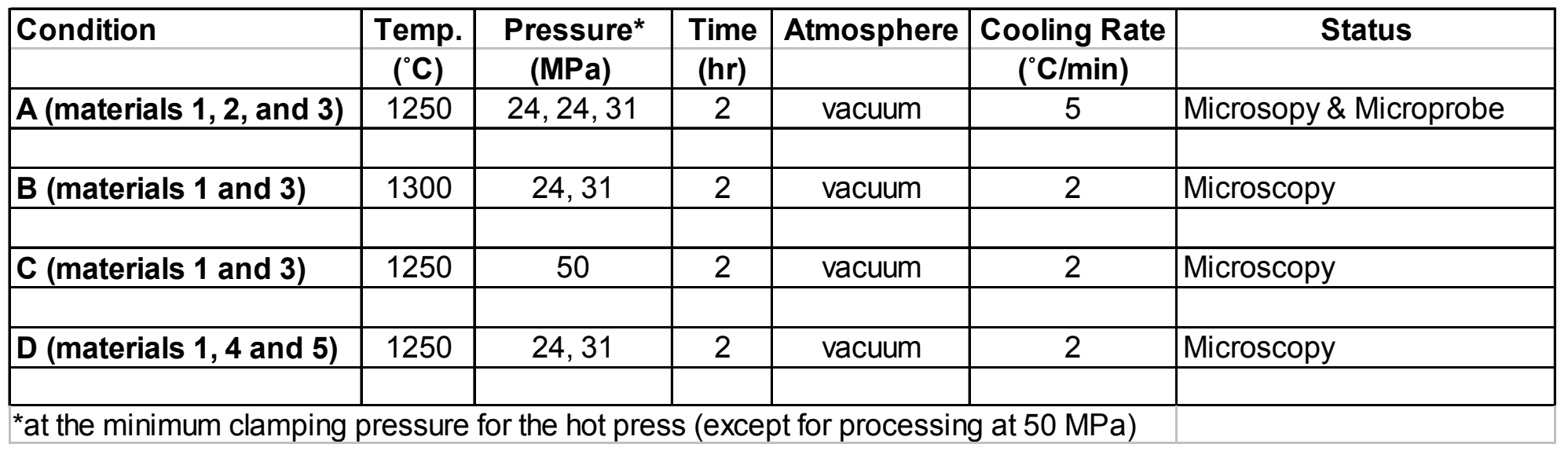




\section{Electron Microprobe Analysis of the "Titanium" Foil}

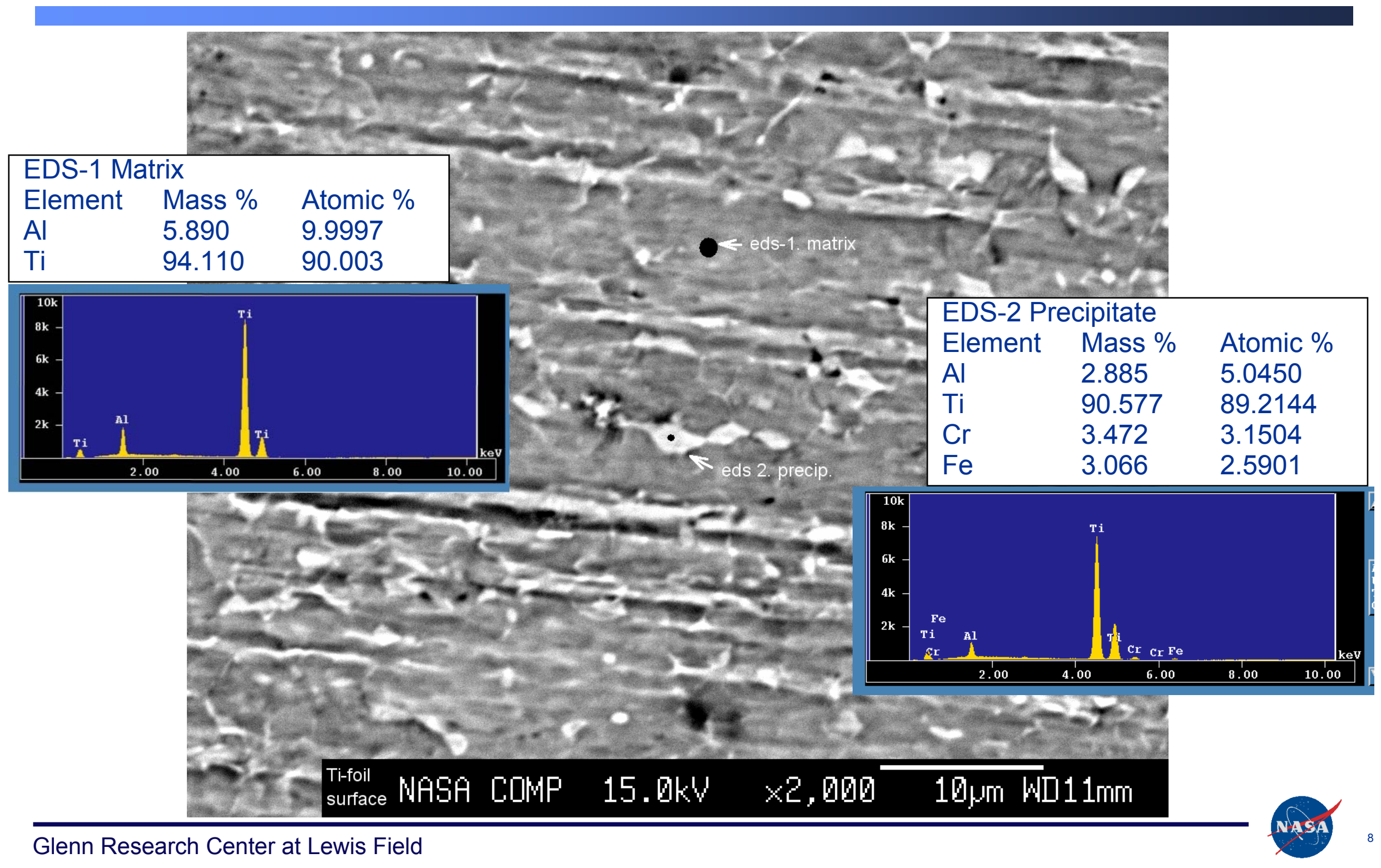




\section{Diffusion Bonds Analysis: Microscopy and Microprobe}

Effect of Material Combinations and Processing Parameters (to be shown on the following slides):

1. Material Combinations of Ti and Substrate $\left(1250^{\circ} \mathrm{C}\right.$ and minimum clamping pressure)

- a-SiC (CRYSTAR from Saint-Gobain) discs joined with a 1.5 mil (38 micron) foil

- CVD $\beta$-SiC (TREX) joined with a 1.5 mil (38 micron) foil

- CVD $\beta-S i C$ (Rohm \& Hass) joined with $~ 10$ micron PVD Ti coating on one of the surfaces

2. Effect of Cooling Rate $\left(1250^{\circ} \mathrm{C}\right.$ and minimum clamping pressure)

- $5^{\circ} \mathrm{C} / \mathrm{min}$ and $2{ }^{\circ} \mathrm{C} / \mathrm{min}$

3. Effect of Higher Processing Temperature

$-1300^{\circ} \mathrm{C}$

4. Effect of a Higher Hot Press Load and Resulting Stress

- $50 \mathrm{MPa}$

5. Effect of Ti Type and Thickness

- 38 micron Ti foil, and $\sim 10$ and $\sim 20$ micron PVD Ti interlayers 


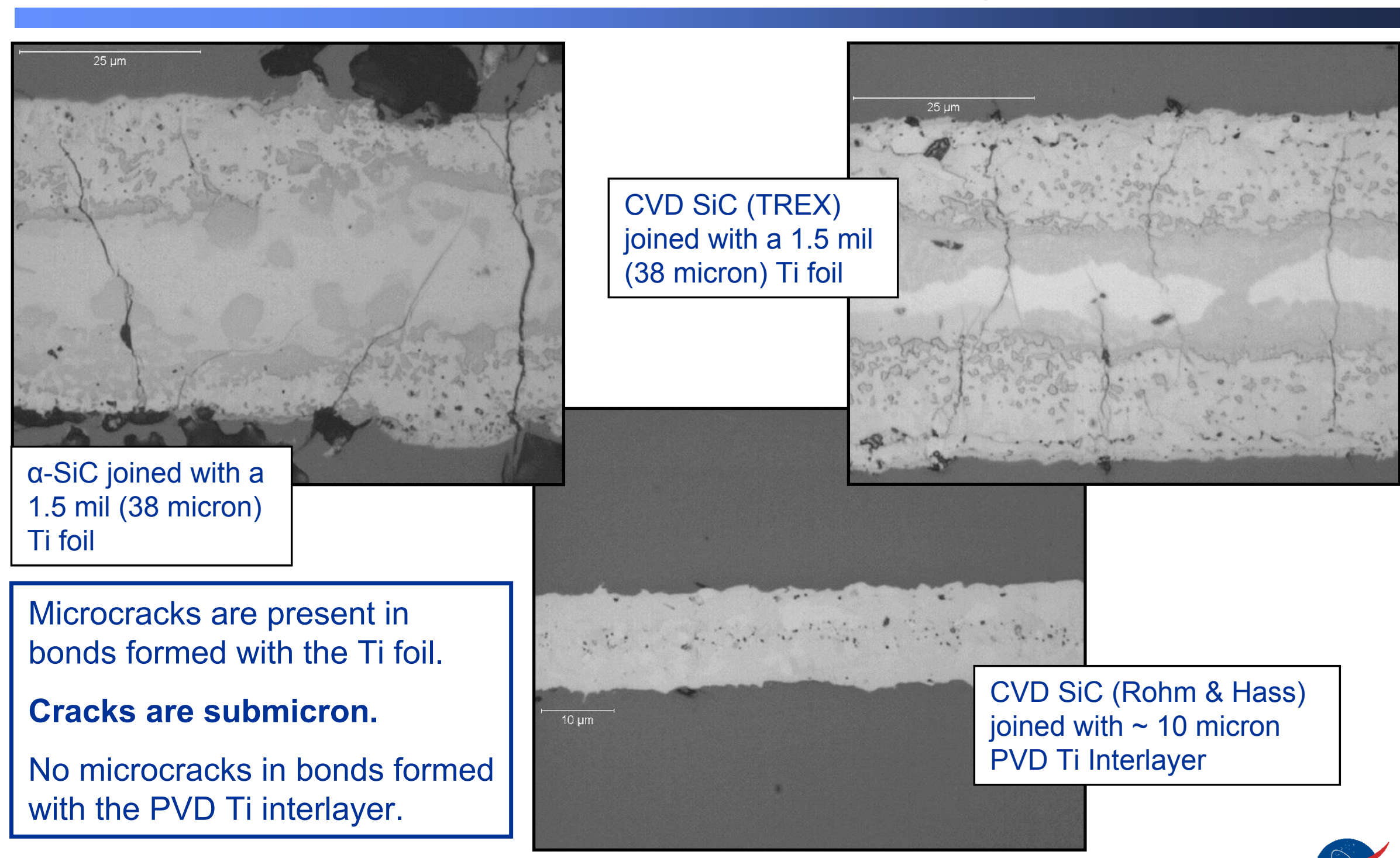




\section{Effects-Slide 2 - Effect of Cooling Rate: 2 and $5^{\circ} \mathrm{C} / \mathrm{min}$ Conditions: $1250{ }^{\circ} \mathrm{C}$, Minimum Clamping Pressure, $2 \mathrm{hr}$ hold, Vacuum}

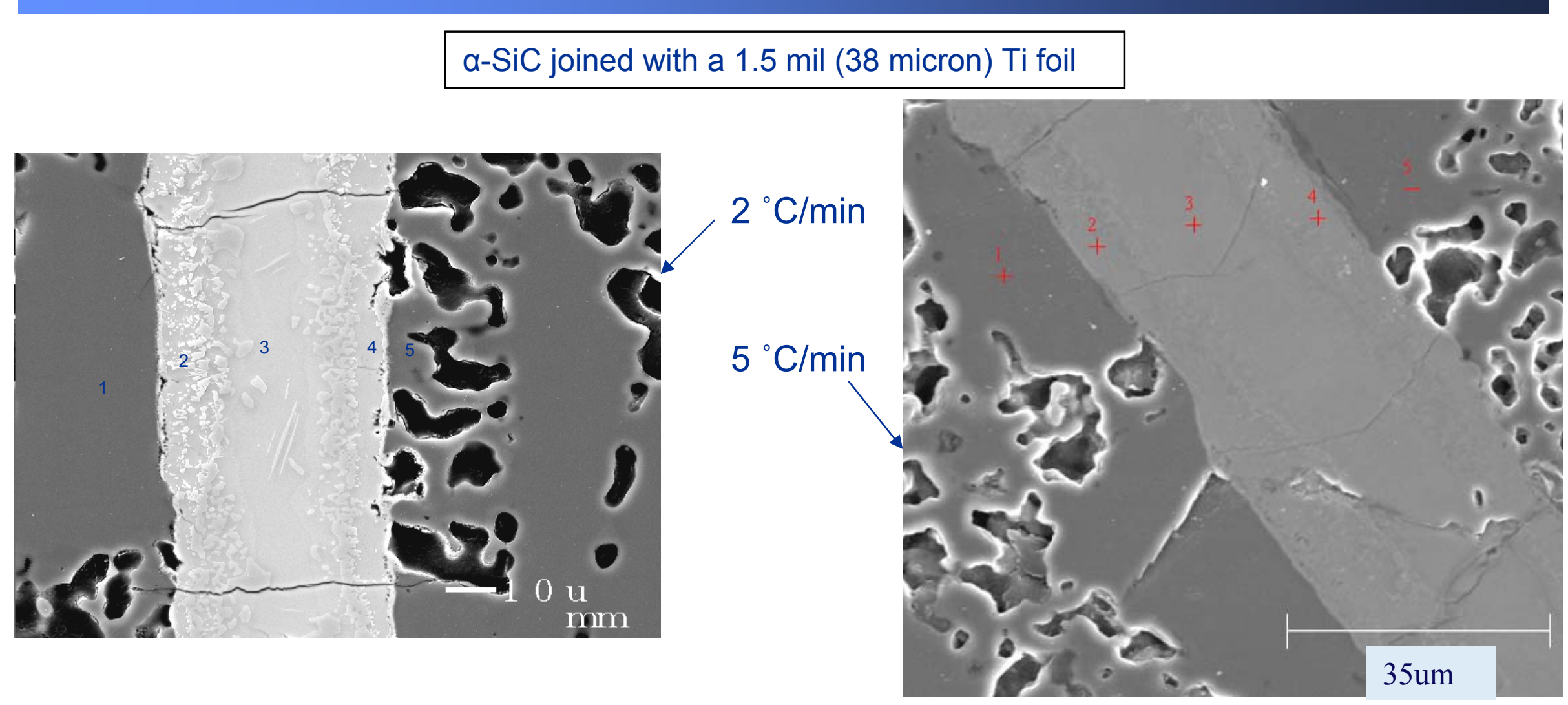

A slower cooling rate of $5{ }^{\circ} \mathrm{C} / \mathrm{min}$ did not alleviate the microcracking. 
Effects-Slide 3 - Effect of Higher Processing Temperature NASA Conditions: $1300^{\circ} \mathrm{C}$, Minimum Clamping Pressure, $2 \mathrm{hr}$ hold, Vacuum, Cooling Rate $2{ }^{\circ} \mathrm{C} / \mathrm{min}$
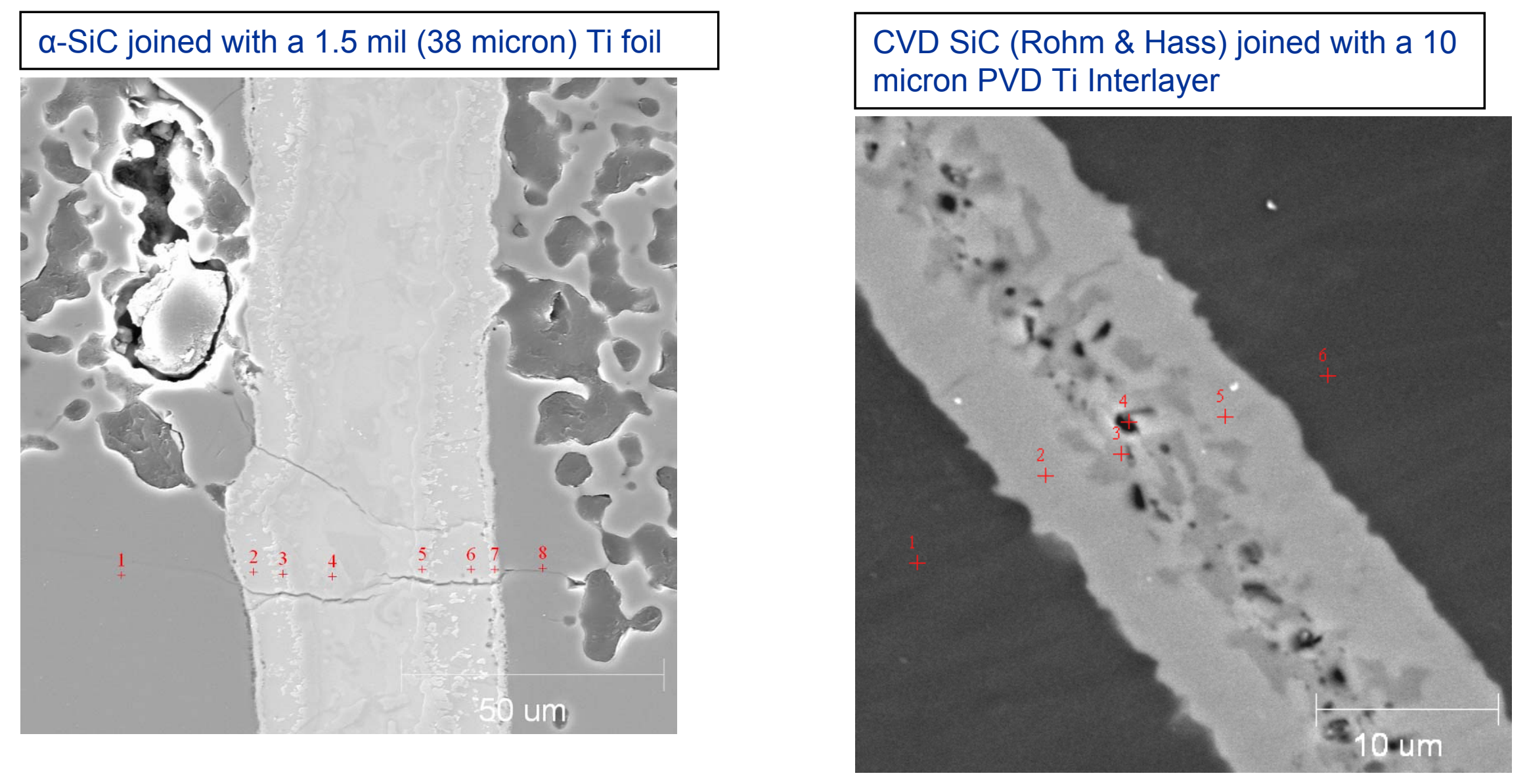

Minimal difference from processing at the higher temperature of $1300^{\circ} \mathrm{C}$. 


\section{Effects-Slide 4 - Effect of Higher Processing Stress Conditions: $1250{ }^{\circ} \mathrm{C}, 50 \mathrm{MPa}, 2 \mathrm{hr}$ hold, Vacuum, Cooling Rate $2{ }^{\circ} \mathrm{C} / \mathrm{min}$}
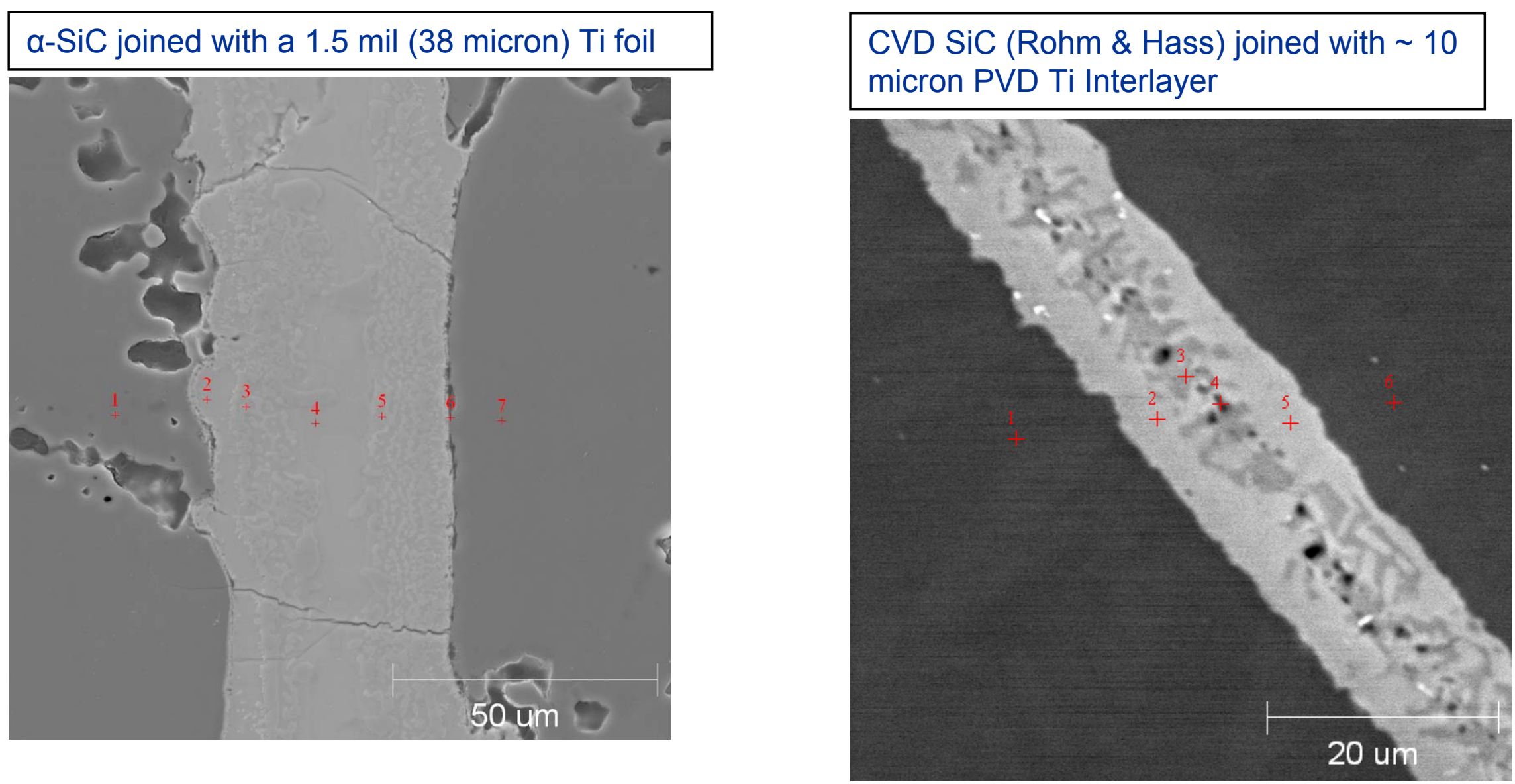

Minimal difference from processing at the higher stress of $50 \mathrm{MPa}$. 


\section{Effects-Slide 5 - Effect of Ti Type and Thickness Conditions: $1250{ }^{\circ} \mathrm{C}, 31 \mathrm{MPa}, 2 \mathrm{hr}$ hold, Vacuum, Cooling Rate $2^{\circ} \mathrm{C} / \mathrm{min}$}
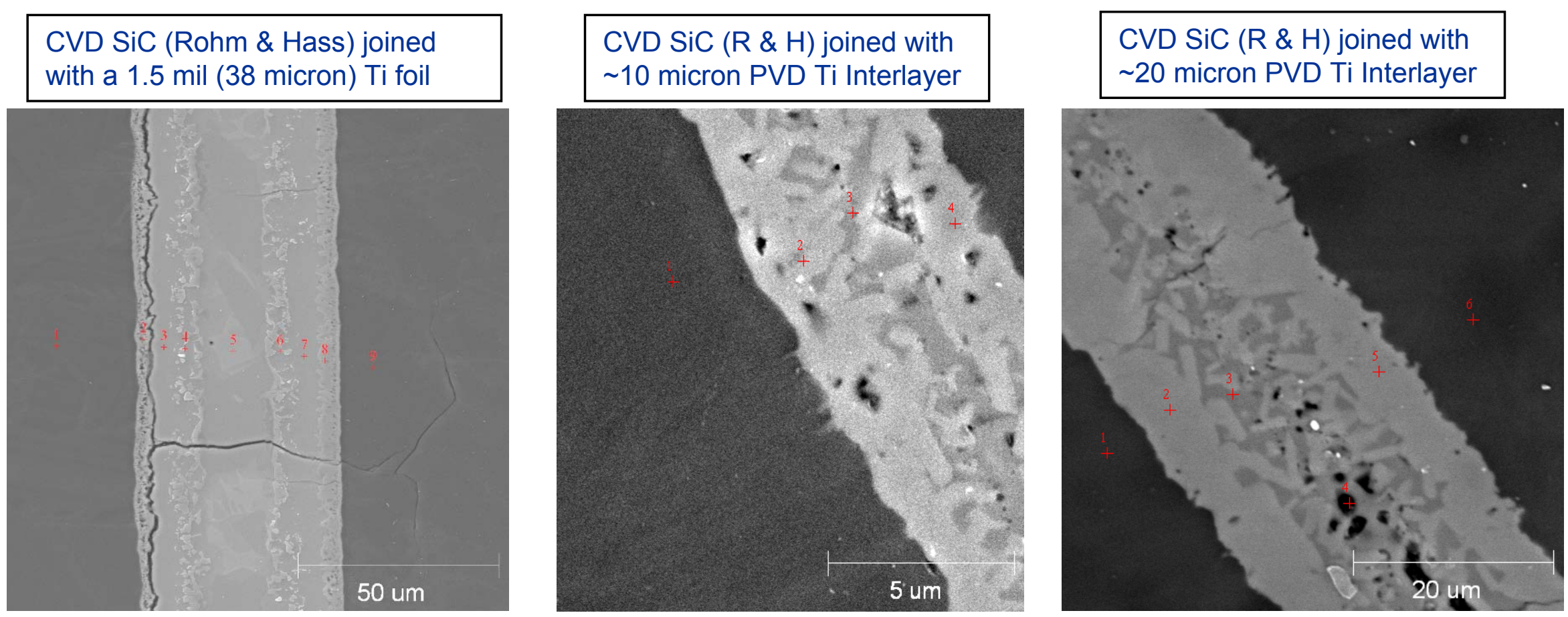

Debonding was observed in the material combination of Ti foil and CVD SiC.

In all cases that the Ti foil was used as the interlayer, microcracking was observed.

Minimal microcracking was observed when a PVD Ti interlayer was used. Well reacted diffusion bond formed when the thickness of the PVD Ti interlayer was doubled. 


\section{Microprobe of $\alpha-S i C$ Reaction Bonded Using Ti Foil Conditions: $1250{ }^{\circ} \mathrm{C}, 24 \mathrm{MPa}, 2 \mathrm{hr}$, vacuum, $5^{\circ} \mathrm{C} / \mathrm{min}$}

Microcracking may be due to the formation of two detrimental phases:

- Phase $\mathrm{B} \mathrm{Ti}{ }_{5} \mathrm{Si}_{3} \mathrm{C}_{\mathrm{X}}-\mathrm{Ti}_{5} \mathrm{Si}_{3}$ if highly anisotropic in its thermal expansion where $\mathrm{CTE}(\mathrm{c}) / \mathrm{CTE}(\mathrm{a})=2.72$ (Schneibel et al).

- Phase $\mathrm{E}-\mathrm{Ti}_{3} \mathrm{Al}$ has low ductility at low temperatures. Al can be in the range of $23-35 \mathrm{~atm} \%$ (Djanarthany et al).

Both phases can contribute to thermal stresses and microcracking during cool down.

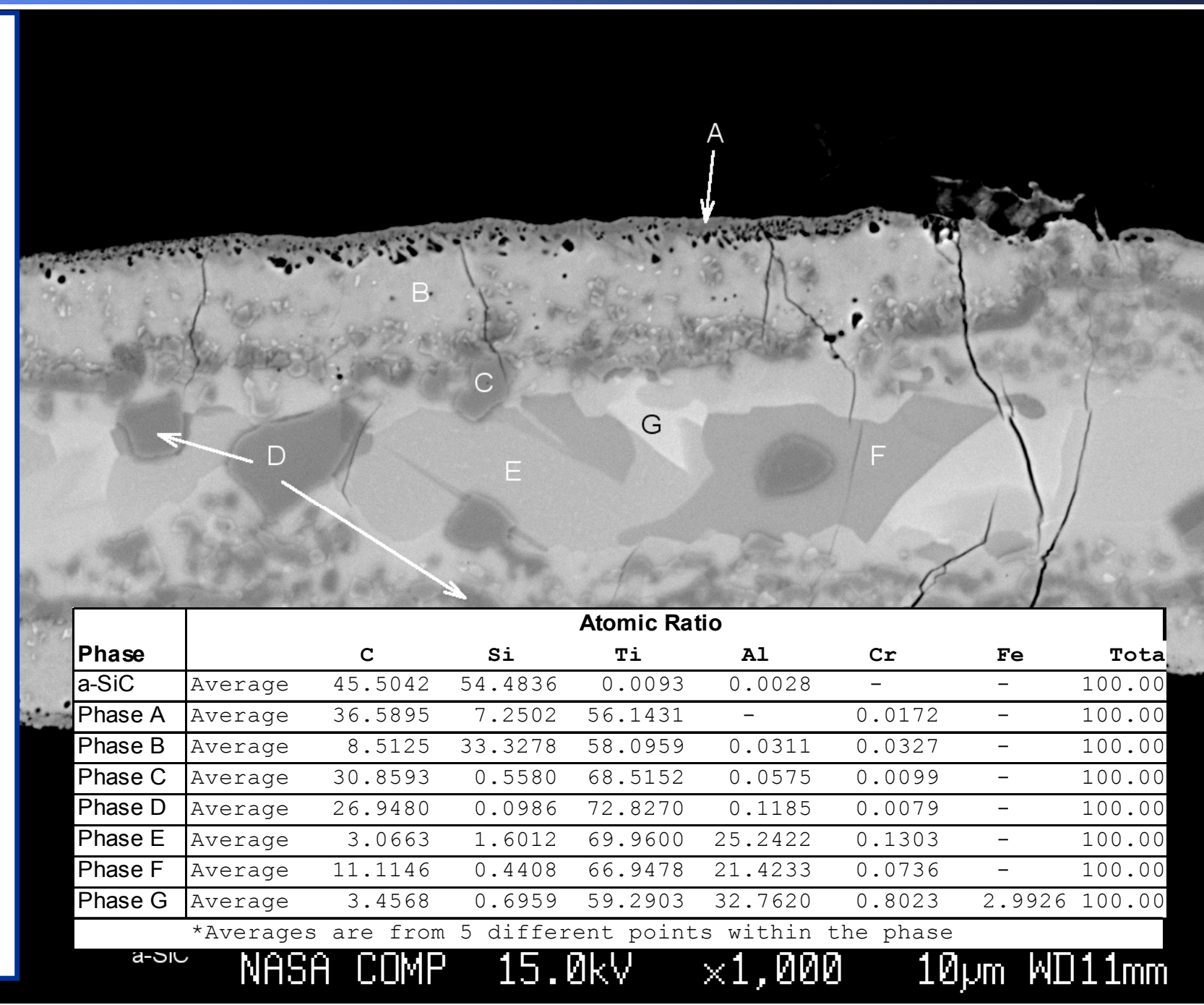




\begin{tabular}{|l|lccccccc|}
\hline & & & \multicolumn{7}{c|}{ Atomic Ratio } \\
Phase & & $\mathbf{C}$ & Si & Ti & Al & Cr & Fe & Total \\
\hline CVD SiC & Average & 45.0724 & 54.9232 & 0.0044 & - & - & - & 100.0000 \\
\hline Phase A & Average & 27.6739 & 17.5240 & 54.7914 & - & 0.0107 & - & 100.0000 \\
\hline Phase B & Average & 7.3882 & 34.1646 & 58.0582 & 0.3384 & 0.0505 & - & 100.0000 \\
\hline Phase C & Average & 6.432 & 0.764 & 73.488 & 19.276 & 0.040 & - & 100.000 \\
\hline Phase D & Average & 1.1908 & 1.0678 & 60.4347 & 35.7833 & 0.4800 & 1.0435 & 100.0000 \\
\hline Phase E & Average & 12.9321 & 0.5829 & 66.3609 & 20.0616 & 0.0342 & 0.0283 & 100.0000 \\
\hline & *Averages & are from & 5 different points within the phase \\
\hline
\end{tabular}

The same detrimental phases of $\mathrm{Ti}_{5} \mathrm{Si}_{3}(\mathrm{~B})$ and $\mathrm{Ti}_{3} \mathrm{Al}(\mathrm{D})$ are formed which can contribute to microcracking during cool down.

Note how cracks appear to originate in Phase B or in the core, however they are absent from outer phase (Phase A)

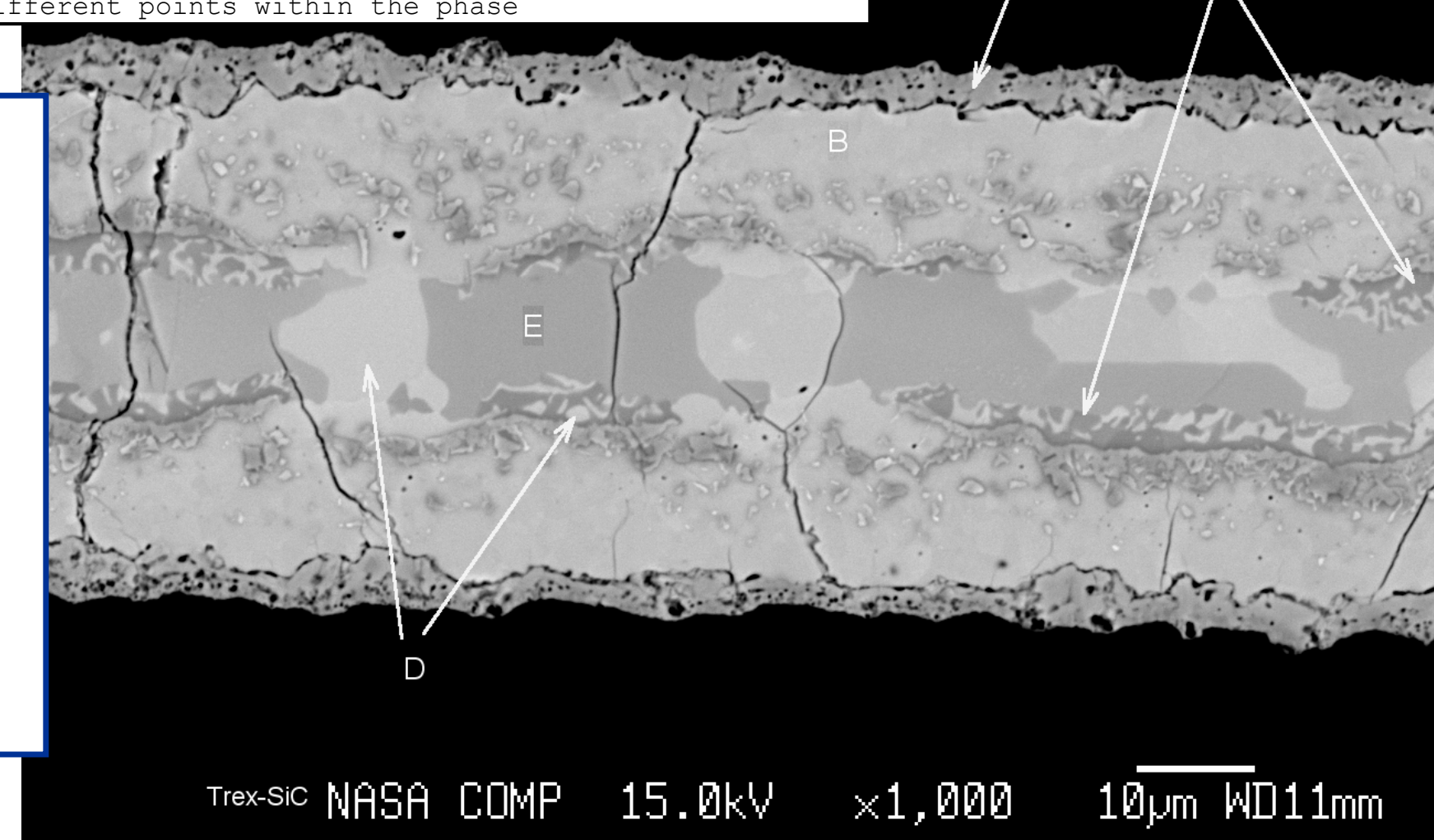




\section{Microprobe of CVD SiC (R \& H) Bonded Using PVD Ti Conditions: $1250{ }^{\circ} \mathrm{C}, 31 \mathrm{MPa}, 2 \mathrm{hr}$, vacuum, $5{ }^{\circ} \mathrm{C} / \mathrm{min}$}

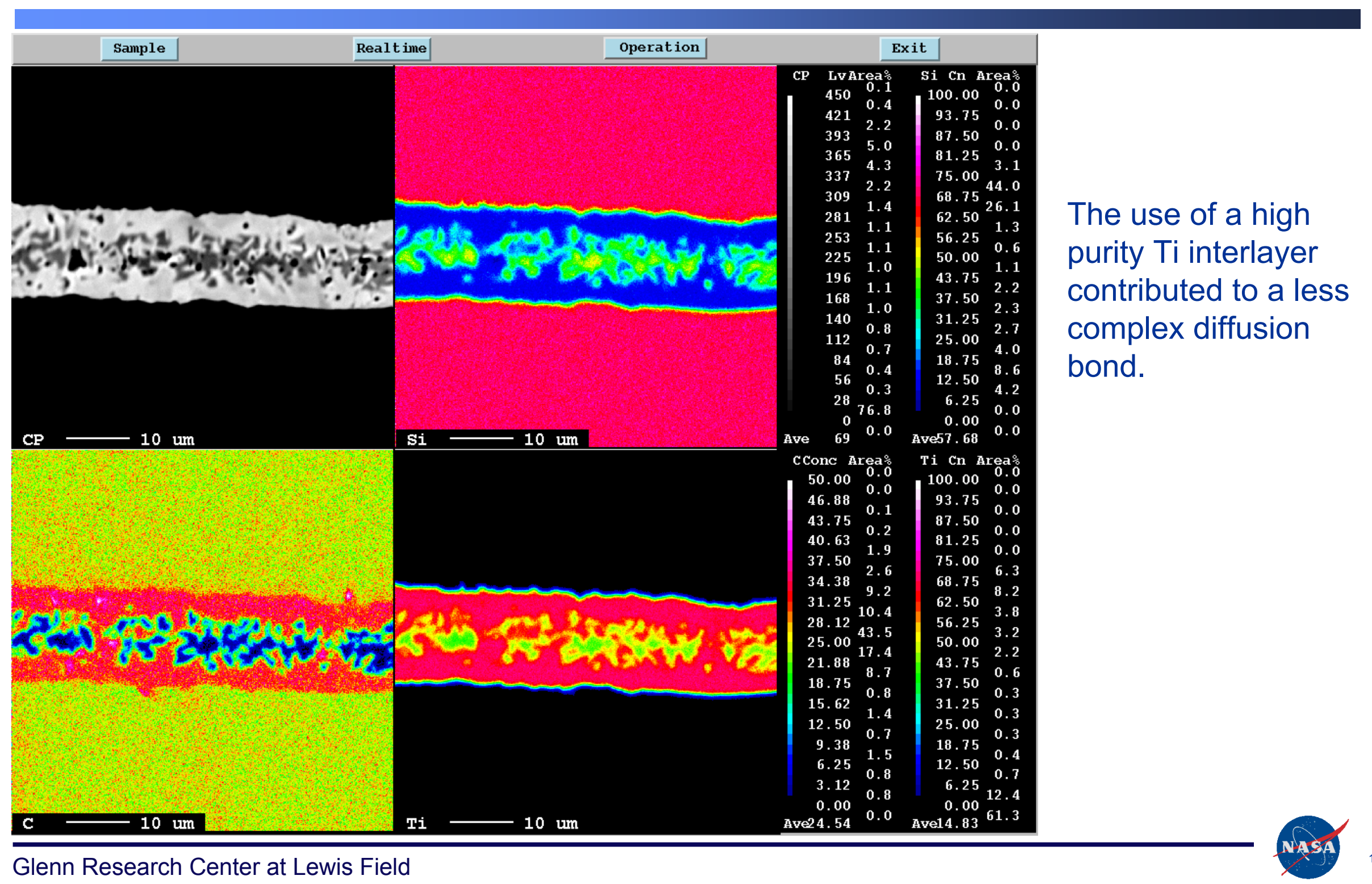




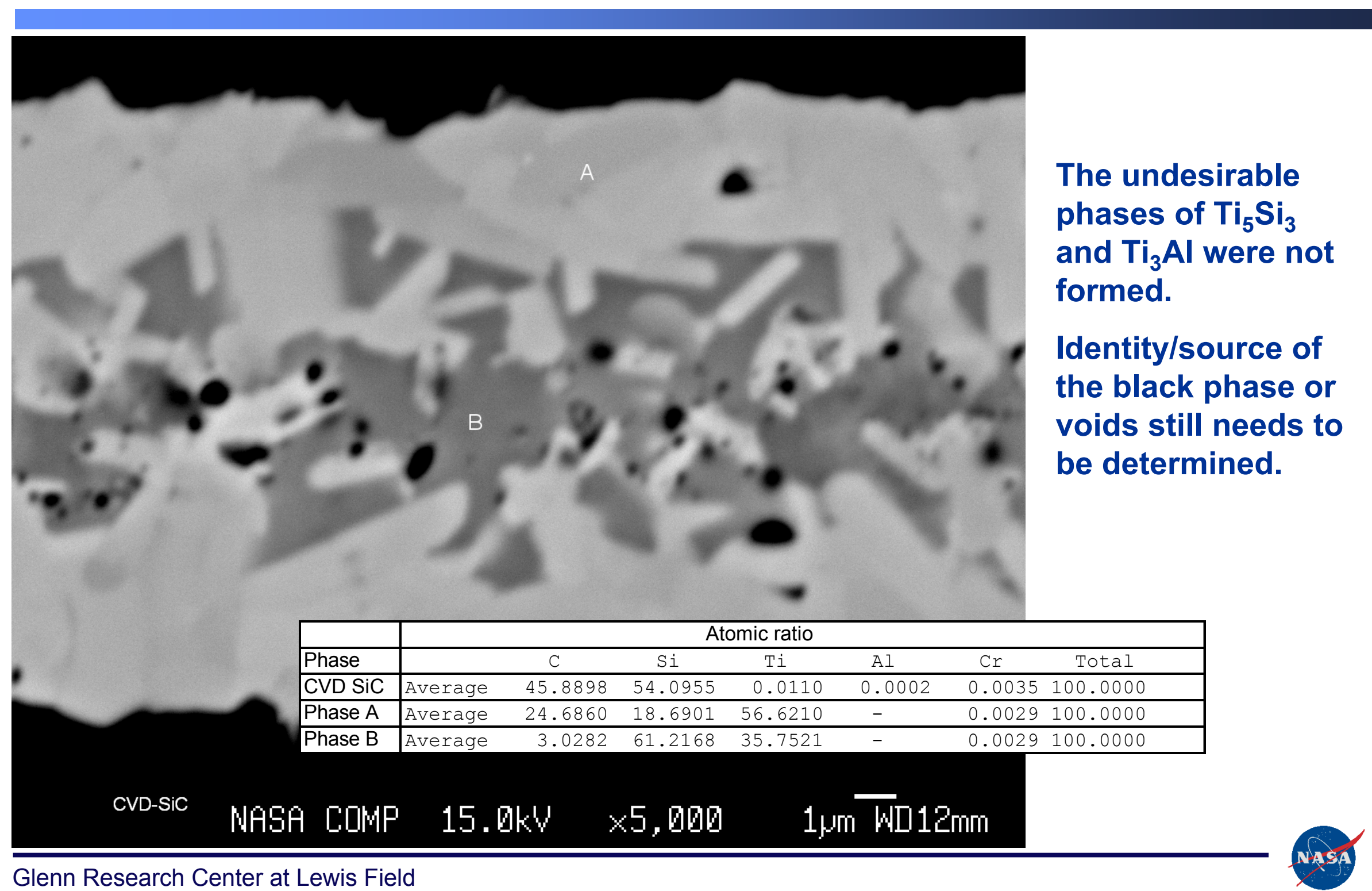




\section{Initial Strength Tests on Diffusion Bonded CVD SiC with a PVD Ti Interlayer}

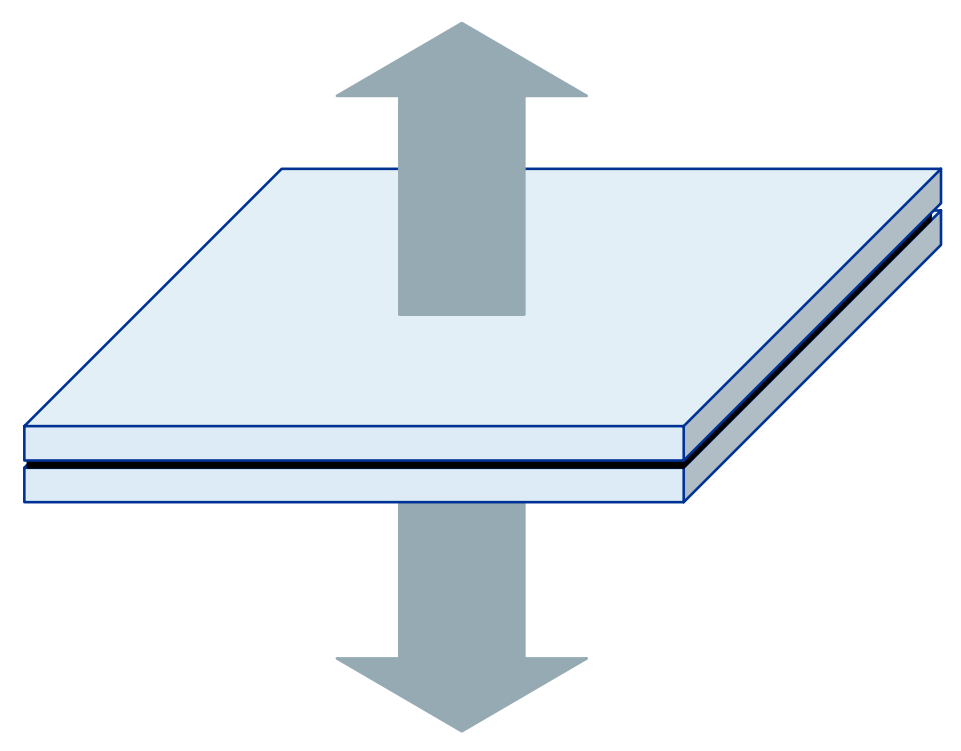

Initial pull test tensile strengths:

$>23.62 \mathrm{MPa}(3.43 \mathrm{ksi})^{*}$

$>28.38 \mathrm{MPa}(4.12 \mathrm{ksi})^{*}$

* failure in the adhesive

The injector application requires a strength of about 3.45-6.89 MPa (0.5 - $1.0 \mathrm{ksi})$.

The new 1" sample design (partially coated disks) will allow for stresses of 62 $\mathrm{MPa}$ (9 ksi) to be applied (due to a large adhesive/pull area compared to the diffusion bond area).
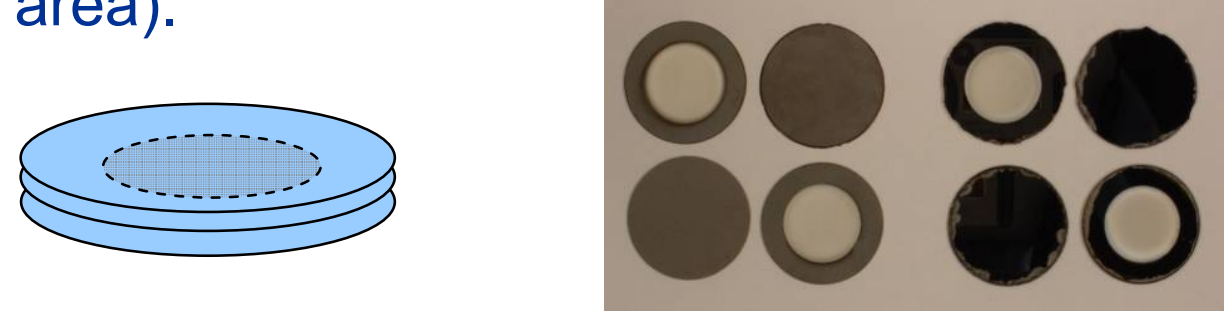


\section{Summary and Conclusions}

- A robust method of bonding $\mathrm{SiC}$ to $\mathrm{SiC}$ has been developed and optimized.

- Diffusion bonds fabricated with the alloyed Ti foil as the interlayer formed microcracks due to the formation of thermally anisotropic and low ductility phases.

- Diffusion bonds fabricated with the PVD Ti coating gave better diffusion bonds than the alloyed Ti foils

- Bonds were uniform with no delaminations.

- Preferred phases were formed which resulted in bonds without microcracks.

- The currently planned sub-element tests will further evaluate this bonding method to determine if it is fully capable of meeting the needs of the proposed injector application - uniform, leak-free bonds with stability and strength retention at temperatures up to $800^{\circ} \mathrm{F}$. 